\title{
Fabrication of Metal Matrix Composite Containing Manganese Nitride Showing Giant Negative Thermal Expansion by Compressive Torsion Processing
}

\author{
Koshi Takenaka $^{1, *}$, Kentaro Otsuka ${ }^{1}$, Yoshihiko Okamoto ${ }^{1}$, Yuji Kume ${ }^{2}$ and Makoto Kobashi ${ }^{3}$ \\ ${ }^{1}$ Department of Applied Physics, Nagoya University, Nagoya 464-8603, Japan \\ ${ }^{2}$ Department of Mechanical Systems Engineering, Yamagata University, Yonezawa 992-8510, Japan \\ ${ }^{3}$ Department of Materials Process Engineering, Nagoya University, Nagoya 464-8603, Japan
}

\begin{abstract}
Antiperovskite manganese nitride $\mathrm{Mn}_{3.1} \mathrm{Zn}_{0.5} \mathrm{Sn}_{0.4} \mathrm{~N}$ was composited with $\mathrm{Al}$ by compressive torsion processing (CTP). This class of nitrides is anticipated for use as a thermal-expansion compensator because of giant negative thermal expansion (NTE). It is difficult to form a composite with molten metal that causes a chemical reaction. To date, only limited success has been achieved. Composites formed by CTP at $573 \mathrm{~K}$ exhibit lower thermal expansion and electrical resistivity than those produced by electric-current sintering. That achievement is attributable to suppressed chemical erosion of the filler by treatment at a lower temperature while the strong mechanical energy strengthens the interface between the filler and the matrix and reduces pores in the material. Compressive torsion processing is a promising method for forming metal matrix composites containing giant NTE fillers. [doi:10.2320/matertrans.MT-M2020363]
\end{abstract}

(Received November 30, 2020; Accepted February 15, 2021; Published March 19, 2021)

Keywords: compressive torsion processing, negative thermal expansion, metal matrix composite, antiperovskite manganese nitride

\section{Introduction}

Highly developed industrial technology increasingly demands precise dimensional control of components that make up devices and equipment. Even the unavoidable thermal expansion of solid materials has become an urgent issue in many fields of industry. Therefore, many attempts have been undertaken to use negative thermal expansion (NTE) materials that contract on heating, which is the opposite behavior of most components. ${ }^{1)}$ NTE phenomena were identified in the $1950 \mathrm{~s}$ for some silicon oxides, including $\mathrm{LiAlSiO}_{4}$ ( $\beta$-eucryptite). ${ }^{2}$ Research on NTE has evolved dramatically over the last two decades, ${ }^{3-7)}$ yielding discoveries of large negative coefficients of linear thermal expansion exceeding $\alpha=-100 \times 10^{-6} \mathrm{~K}^{-1}$ (Ref. 8) and total volume change related to NTE exceeding $8 \% .^{9)}$ Along with this progress, many attempts have been undertaken to develop composite materials containing these NTE materials as a thermal-expansion compensator. ${ }^{10-13)}$

However, unlike chemically stable oxides such as $\mathrm{SiO}_{2}$ (silica) and $\mathrm{Al}_{2} \mathrm{O}_{3}$ (alumina), most NTE materials are chemically reactive at high temperatures. They are particularly difficult to composite with a metal. ${ }^{14-17)}$ In the case of manganese nitrides, ${ }^{18)}$ a prototypical giant NTE material, conventional melting and infiltration methods cannot be applied because of their high chemical reactivity with molten metals. Even with the pressure infiltration method, only limited sizes are available. ${ }^{19,20)}$ Powder metallurgy such as electric-current sintering, which can be completed quickly and at lower temperatures, is successful in forming composites. $^{21-25)}$ Even using powder metallurgy method, the filler is eroded into the matrix by the heating process. The thermal-expansion controlling effects are limited. ${ }^{26)}$ For the industrial use of giant NTE materials, the establishment of their composite technology persists as a challenge that remains unmet.

*Corresponding author, E-mail: takenaka@nuap.nagoya-u.ac.jp
We specifically examined a severe plastic deformation method that can consolidate composite powders at even lower temperatures than those used for the electric-current sintering method. Earlier studies have demonstrated that the high-pressure torsion method, ${ }^{27,28)}$ which uses shear deformation under high pressure, can consolidate metal powder and produce a composite material at low temperatures. ${ }^{29-31)}$ Furthermore, compressive torsion processing (CTP), which simultaneously applies compressive and torsional loading to a specimen with upper and lower dies in a cylindrical container, ${ }^{32)}$ enables solid-state recycling of aluminum chips and fabrication of composite materials via a powder processing route at low pressure without deforming its shape. ${ }^{33,34)}$ For present study, manganese nitride and aluminum were composited by CTP. Manganese nitride/Al composites produced using CTP have shown lower thermal expansion and higher electrical conductivity than those made using conventional electric-current sintering. Additionally, the pores in the CTP composite are fewer than that in the counterpart. Hereinafter, the superiority of CTP over electriccurrent sintering is discussed along with future issues in the composite of NTE filler and the metal matrix.

\section{Experimental}

The thermal-expansion compensator, antiperovskite manganese nitride $\mathrm{Mn}_{3.1} \mathrm{Zn}_{0.5} \mathrm{Sn}_{0.4} \mathrm{~N}$, was prepared using solidstate reactions with powders of $\mathrm{Mn}_{2} \mathrm{~N}$ and pure elements $\mathrm{Zn}$ and Sn (99.9\% purity; 30-50 $\mu \mathrm{m}$ particle size). ${ }^{22)}$ The obtained $\mathrm{Mn}_{3.1} \mathrm{Zn}_{0.5} \mathrm{Sn}_{0.4} \mathrm{~N}$ was pulverized with an agate mortar to $30-50 \mu \mathrm{m}$ particles. After mixing these nitride and aluminum (99.99\% purity; $3 \mu \mathrm{m}$ particle size) powders in a volume ratio of $30: 70$, packed them in a container, we consolidated them using CTP $(573 \mathrm{~K}$ temperature $T, 100 \mathrm{MPa}$ compression, five rotations at a speed of $5 \mathrm{rpm}$ ) to produce a cylindrical composite $\left.(\varphi 40 \mathrm{~mm} \times 10 \mathrm{~mm}) .{ }^{32}\right)$ The volume fraction was ascertained based on the material weight using the respective specific gravities of 7.0 and 2.7 for 
$\mathrm{Mn}_{3.1} \mathrm{Zn}_{0.5} \mathrm{Sn}_{0.4} \mathrm{~N}$ and $\mathrm{Al}^{22)}$ For comparison, we also obtained the composite by an electric-current sintering. The nitride and $\mathrm{Al}$ mixed powder was packed in a graphite die $(\varphi 15 \mathrm{~mm} \times 4 \mathrm{~mm})$, which was installed in a spark plasma sintering (SPS) furnace (Syntex Lab; SPS Syntex Inc.). ${ }^{22)}$ Sintering was conducted under $40 \mathrm{MPa}$ pressure at $733 \mathrm{~K}$ for $7 \mathrm{~min}$ in vacuum $\left(<10^{-1} \mathrm{~Pa}\right)$. Hereinafter, the composites formed by the spark plasma sintering and the compressive torsion processing are designated respectively as SPS and CTP composites.

The sample surfaces were observed using a scanning electron microscope (SEM, VE-7800; Keyence). To verify the chemical reaction between the metal matrix and the thermal-expansion compensator, we analyzed the chemical composition of the interface region of the metal matrix composites (MMCs) using energy dispersive X-ray spectroscopy (EDX, Genesis 2000K; EDAX Inc.). Chemical identification and the crystal structure analysis were conducted at $295 \mathrm{~K}$ using X-ray powder diffraction (XRD) with $\mathrm{Cu} K \alpha$ radiation (RINT2000; Rigaku Corp.). Porosity of the composites was estimated using Archimedes' method (SD-200L; Alfa Mirage Co. Ltd.). For physical measurements, the formed composites were cut into rectangular shapes: $4 \mathrm{~mm} \times 4 \mathrm{~mm} \times 12 \mathrm{~mm}$ for dilatometry and $2 \mathrm{~mm} \times$ $1 \mathrm{~mm} \times 6 \mathrm{~mm}$ for electrical resistivity measurements. Specimens of the CTP composite were cut out while avoiding the center axis and lateral edges of rotation as well as the upper and lower surfaces (Fig. 1). For the SPS composite, specimens were cut out from the center. Linear thermal expansion $\Delta L(T) / L$ was measured using a laser-interference dilatometer (LIX-2; Ulvac Technologies Inc.). Temperature dependence of electrical resistivity $\rho(T)$ was measured using a conventional four-probe technique (2182; Keithley Instruments Inc.). Both physical quantities are averaged over the bulk-sized specimens, which are large amounts of material compared to the entire disk-shaped composite sample.

\section{Results}

Figure 2 presents the XRD profile of $30 \mathrm{vol} \%$ $\mathrm{Mn}_{3.1} \mathrm{Zn}_{0.5} \mathrm{Sn}_{0.4} \mathrm{~N} / \mathrm{Al}$ composites formed using SPS and

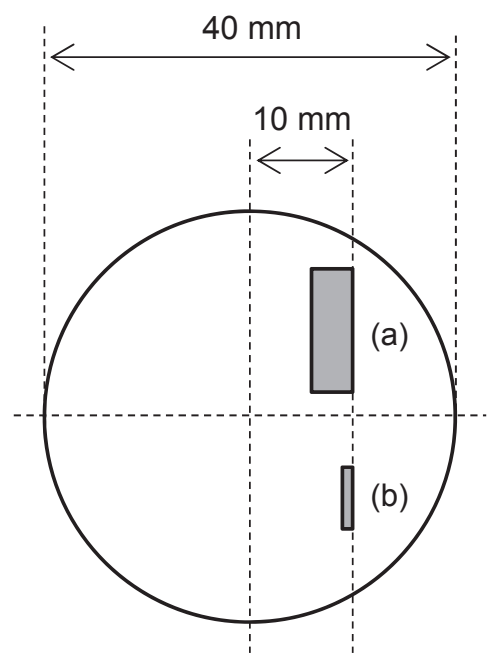

Fig. 1 Positions of cutouts from the CTP composite specimens for dilatometry (a) and electrical resistivity (b) measurements.
CTP methods. For comparison, the profiles of pure $\mathrm{Al}$ and $\mathrm{Mn}_{3.1} \mathrm{Zn}_{0.5} \mathrm{Sn}_{0.4} \mathrm{~N}$ are also shown. Insets are magnified profiles in the range of $64-68 \mathrm{deg}$. For both composites, the XRD profile after processing is a superimposition of the individual patterns of the matrix and the filler, except for the appearance of new minor peaks near $41.8 \mathrm{deg}$ and $43.5 \mathrm{deg}$, which represents that the chemical reaction between the matrix and the filler is limited. For MMCs to function, only a very limited area of the interface between the matrix and the filler undergoes a chemical reaction to bond the two firmly. The others must remain unchanged and retain their unique properties. The present XRD evaluation seems to support it.

The composite formation effect on the matrix and the filler can be evaluated by comparing details of the XRD peak width and shape (Insets of Fig. 2). First, examining the $\mathrm{Mn}_{3.1} \mathrm{Zn}_{0.5} \mathrm{Sn}_{0.4} \mathrm{~N}$ filler, the peak splitting observed in the pure nitride profile becomes unclear for both SPS and CTP, but the spread of the peak width is not confirmed. For Al matrix, the peak width became broader for both composites, but that for CTP is much broader than that of SPS. Crystallite sizes were estimated using Scherrer's equation to be 75$86 \mathrm{~nm}, 45-53 \mathrm{~nm}$, and $39-42 \mathrm{~nm}$ for pure $\mathrm{Al}, \mathrm{Al}$ dispersed in SPS, and Al dispersed in CTP, respectively, using Scherrer's equation. The discussion presented above suggests that the shear stress during CTP introduced much more disorder into the $\mathrm{Al}$ crystal lattice. ${ }^{31)}$

Figure 3 portrays microscopic SEM images of $30 \mathrm{vol} \%$ $\mathrm{Mn}_{3.1} \mathrm{Zn}_{0.5} \mathrm{Sn}_{0.4} \mathrm{~N} / \mathrm{Al}$ composites. The matte-gray and glossygray regions respectively correspond to the $\mathrm{Al}$ matrix and the

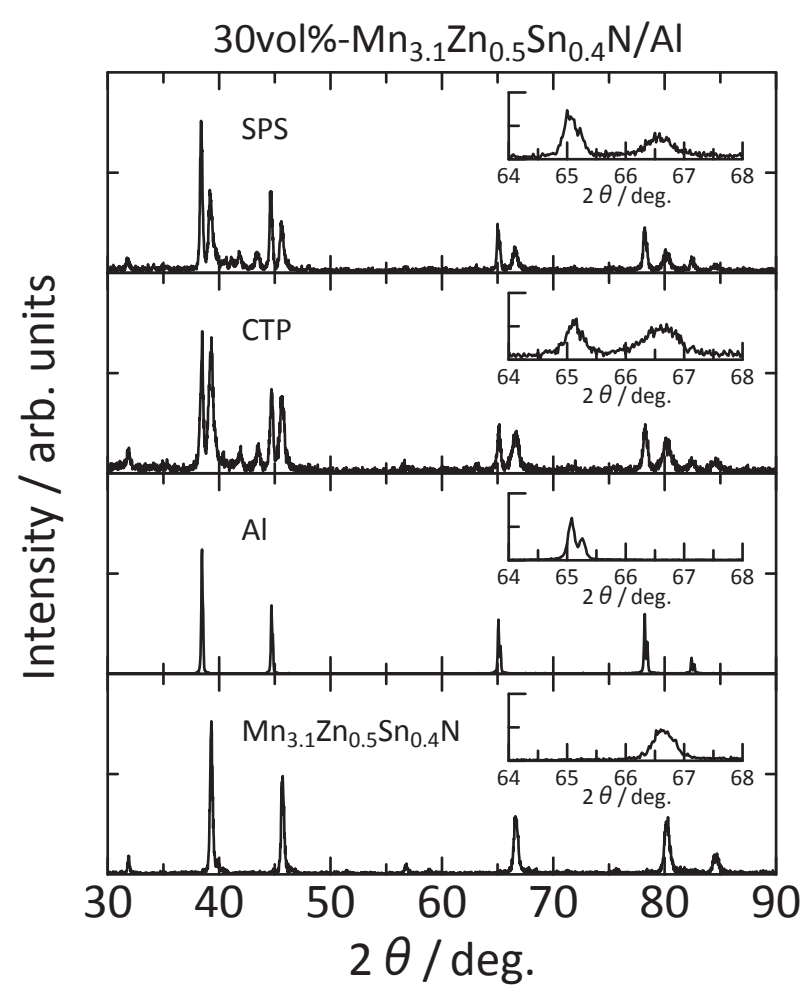

Fig. 2 X-ray diffraction of $30 \mathrm{vol} \%-\mathrm{Mn}_{3.1} \mathrm{Zn}_{0.5} \mathrm{Sn}_{0.4} \mathrm{~N} / \mathrm{Al}$ composites formed by spark plasma sintering (SPS) and compressive torsion processing (CTP). Insets show magnified profiles in the range of 64-68 degrees. Details of fabrication conditions are described in the text. Profiles of pure $\mathrm{Al}$ and $\mathrm{Mn}_{3.1} \mathrm{Zn}_{0.5} \mathrm{Sn}_{0.4} \mathrm{~N}$ are also shown for comparison. Data were collected at $295 \mathrm{~K}$. 

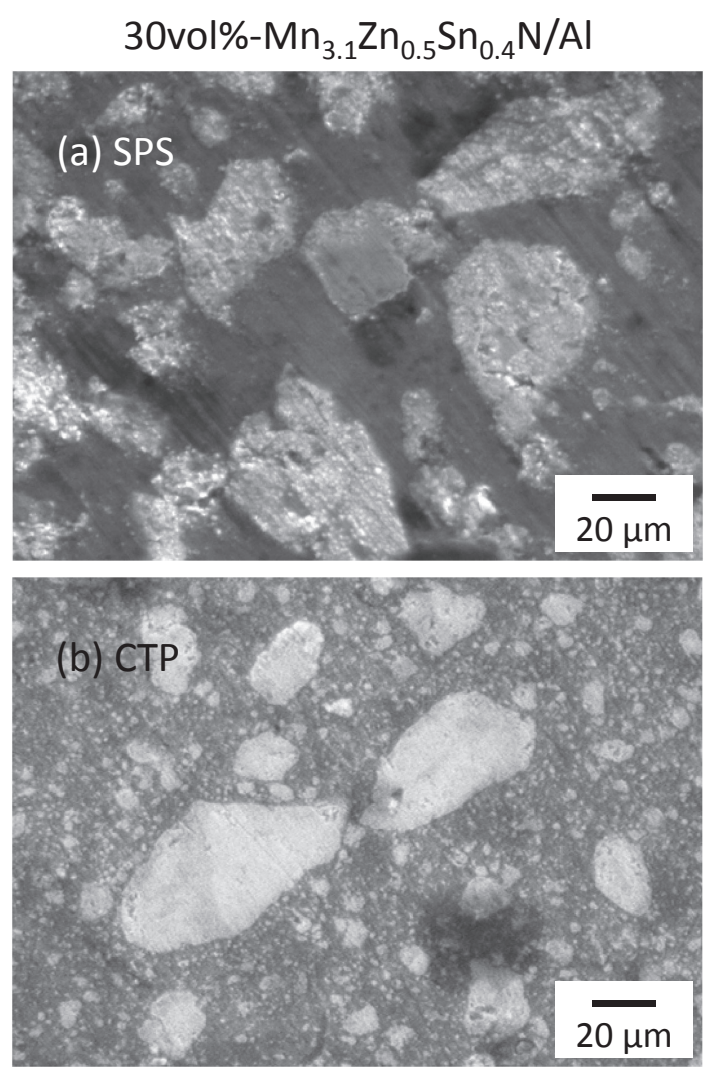

Fig. 3 Microscopic images obtained by scanning electron microscopy of 30 vol\%- $\mathrm{Mn}_{3.1} \mathrm{Zn}_{0.5} \mathrm{Sn}_{0.4} \mathrm{~N} / \mathrm{Al}$ composites formed by SPS (a) and CTP (b). Matte-gray and glossy-gray regions respectively represent the matrix and the filler. Dark shadow regions represent residual pores.

nitride filler. Dark shadows that appear sporadically in some places are pores. The filler particle size is not uniform because it was not controlled, but the filler is uniformly dispersed in the composites. Furthermore, although some pores remain, they are not necessarily at the interface between the matrix and the filler; both are tightly combined. In particular, the pores in the CTP composite are markedly fewer than in the SPS composite, which is true for the materials throughout the sample. From preliminary measurements using Archimedes' method, the porosities of the SPS and CTP composites were roughly estimated respectively to be $4-8 \%$ and $2-6 \%$. This finding suggests that the CTP is less porous than the SPS, although it is difficult to estimate the absolute value of porosity. Another characteristic feature is that the filler dispersed in the CTP includes numerous small grains. Therefore, the filler was crushed during CTP, which is typical of torsion processing methods. ${ }^{27)}$

Figure 4(a) displays linear thermal expansion $\Delta L(T) / L$ obtained on a warming process for $30 \mathrm{vol} \%$ $\mathrm{Mn}_{3.1} \mathrm{Zn}_{0.5} \mathrm{Sn}_{0.4} \mathrm{~N} / \mathrm{Al}$ composites. For comparison, the data for pure $\mathrm{Al}$ and $\mathrm{Mn}_{3.1} \mathrm{Zn}_{0.5} \mathrm{Sn}_{0.4} \mathrm{~N}$ are also shown. Moreover, to clarify differences between SPS and CTP, the thermal expansion near the NTE operating temperatures of $\mathrm{Mn}_{3.1} \mathrm{Zn}_{0.5} \mathrm{Sn}_{0.4} \mathrm{~N}$ is magnified in Fig. 4(b). Reflecting the NTE of $\mathrm{Mn}_{3.1} \mathrm{Zn}_{0.5} \mathrm{Sn}_{0.4} \mathrm{~N}$ at 340-370 K, thermal expansion of the composites is also suppressed at about the same $T$ region. The results of SPS and CTP are coincident at temperatures between $300 \mathrm{~K}$ and $340 \mathrm{~K}$, but the thermal expansion of CTP is more suppressed than SPS in the
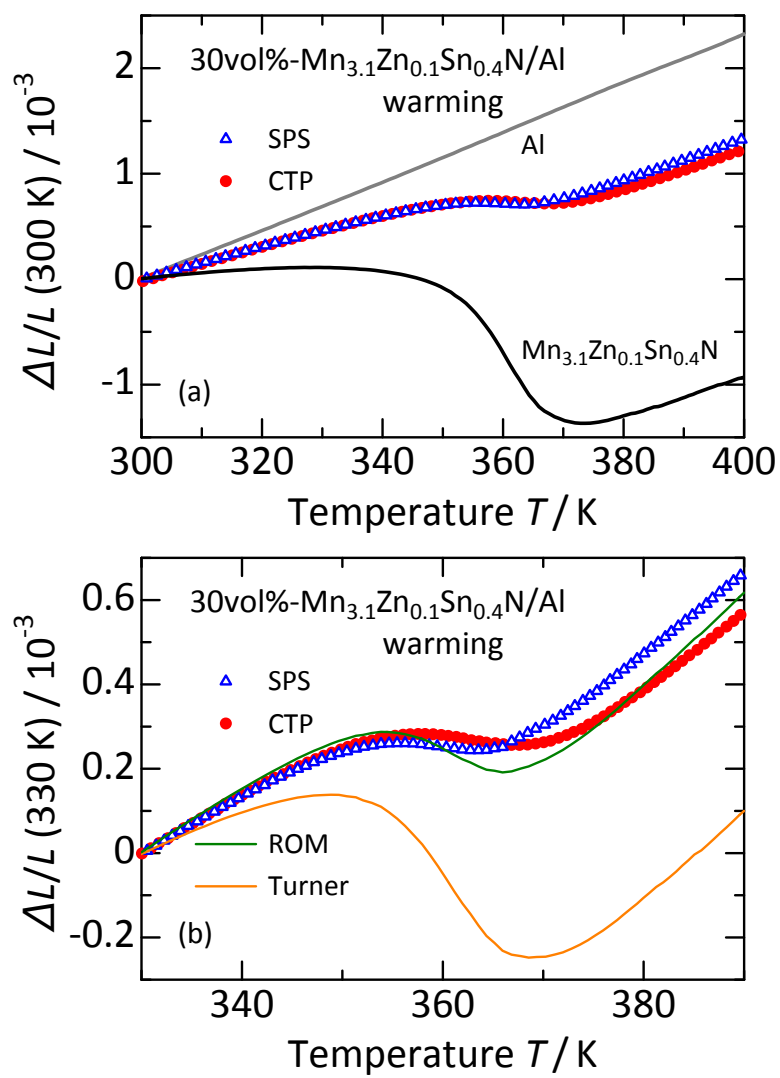

Fig. 4 (a) Linear thermal expansion $\Delta L / L$ of 30 vol\%- $\mathrm{Mn}_{3.1} \mathrm{Zn}_{0.5} \mathrm{Sn}_{0.4} \mathrm{~N} /$ Al composites formed by SPS (open triangle) and CTP (solid circle). (b) Experimental plots of linear thermal expansion and curves calculated using ROM and Turner's model for 30 vol\% $-\mathrm{Mn}_{3.1} \mathrm{Zn}_{0.5} \mathrm{Sn}_{0.4} \mathrm{~N} / \mathrm{Al}$ composites are shown.

operating $T$ range of NTE. Thermal expansion of the Al matrix is suppressed more effectively in CTP than in SPS.

The thermal expansion of the obtained composites was analyzed using two theoretical bounds, rule of mixture (ROM) and Turner's models, in which particles of an isotropic thermal-expansion-compensating filler are dispersed uniformly in an isotropic matrix. ${ }^{1,35)}$ The former bound is given by assuming that thermally induced stress is uniform everywhere throughout a composite, which is equivalent to the assumption that the matrix and the filler exhibit their own thermal expansion independently. Consequently, the thermal expansion of a composite is given by the volumeweighted sum of the contributions from the matrix and the dispersed filler.

$$
\alpha_{\mathrm{c}}=v_{\mathrm{m}} \alpha_{\mathrm{m}}+v_{\mathrm{f}} \alpha_{\mathrm{f}}
$$

Here, subscripts $c, m$, and $\mathrm{f}$ respectively represent the composite, matrix, and filler. In addition, $v_{\mathrm{m}}$ and $v_{\mathrm{f}}$ respectively denote the volume fractions of the matrix and the filler. In addition, $v_{\mathrm{m}}+v_{\mathrm{f}}=1$.

The latter bound is given by the approximation that thermally induced strain is uniform throughout a composite because of elastic interactions at the interfaces between the matrix and the filler, as proposed first by Turner.

$$
\alpha_{\mathrm{c}}=\left(v_{\mathrm{m}} E_{\mathrm{m}} \alpha_{\mathrm{m}}+v_{\mathrm{f}} E_{\mathrm{f}} \alpha_{\mathrm{f}}\right) /\left(v_{\mathrm{m}} E_{\mathrm{m}}+v_{\mathrm{f}} E_{\mathrm{f}}\right)
$$

In that equation, $E$ is Young's modulus. In eq. (2), the element with the larger elastic modulus contributes more to 
thermal expansion of the composite. For the present analysis, $E_{\mathrm{m}}$ and $E_{\mathrm{f}}$ are assumed, respectively, to be $70 \mathrm{GPa}$ and $200 \mathrm{GPa} ;{ }^{22)}$ also, $\alpha_{\mathrm{m}}>\alpha_{\mathrm{f}}$ is satisfied in the displayed $T$ region. Therefore, eq. (1) gives the upper bound; eq. (2) gives the lower bound for $\alpha_{\mathrm{c}}$. Because the Young's modulus of the thermal-expansion compensator is greater than that of the matrix, thermal expansion suppression that is greater than the volume fraction can be expected.

Figure 4(b) also shows the ROM and Turner estimates which are calculated when the volume ratio of $\mathrm{Al}$ to $\mathrm{Mn}_{3.1} \mathrm{Zn}_{0.5} \mathrm{Sn}_{0.4} \mathrm{~N}$ is 7:3. Comparisons with them indicate that the thermal expansion of SPS is greater than ROM, whereas the thermal expansion of CTP is equal to or rather smaller than ROM. In earlier research on MMCs containing the manganese nitrides, the thermal expansion is actually the same as ROM or rather large, presumably because of interfacial imperfections and the progress of chemical reactions. $^{22,23)}$

In a thermal-expansion controlled MMC, it is ideal that the thermal expansion and other physical properties such as conductivity be controllable independently. In many cases, it is necessary to maintain high electrical and thermal conductivities, which are the characteristics of matrix metals, to the greatest degree possible. Figure 5 shows $T$ dependent electrical resistivity $\rho(T)$ measured on 30 vol\%$\mathrm{Mn}_{3.1} \mathrm{Zn}_{0.5} \mathrm{Sn}_{0.4} \mathrm{~N} / \mathrm{Al}$ composites. Earlier reports ${ }^{26}$ ) have described that the electrical conductivity of composites is affected strongly by the state of the matrix-filler interface. It is therefore an important indicator for evaluating the state of the interface. In this experiment, $\rho$ of CTP was less than half that of SPS, suggesting considerable improvement at the interface. This reduction of $\rho$ is also regarded as further evidence that CTP has fewer pores than SPS has. In general, pores also degrade electrical conductivity considerably.

To gain deeper insight into the interfacial state, quantitative analysis of $\rho$ was performed using the Wiedemann-Franz law and the ROM on electrical conductivity $\sigma=1 / \rho$ based on the parallel circuit model of

$$
\sigma_{\mathrm{c}}=v_{\mathrm{m}} \sigma_{\mathrm{m}}+v_{\mathrm{f}} \sigma_{\mathrm{f}}
$$

Because $\rho$ of $\mathrm{Al}$ and $\mathrm{Mn}_{3.1} \mathrm{Zn}_{0.5} \mathrm{Sn}_{0.4} \mathrm{~N}$ at room temperature are $3 \mu \Omega \mathrm{cm}^{36)}$ and $300 \mu \Omega \mathrm{cm},{ }^{37)}$ respectively, resistivity of the $30 \mathrm{vol} \%-\mathrm{Mn}_{3.1} \mathrm{Zn}_{0.5} \mathrm{Sn}_{0.4} \mathrm{~N} / \mathrm{Al}$ composite is estimated as $\rho_{\mathrm{ROM}}=4.3 \mu \Omega \mathrm{cm}$ according to ROM. The values of $\rho$ of the

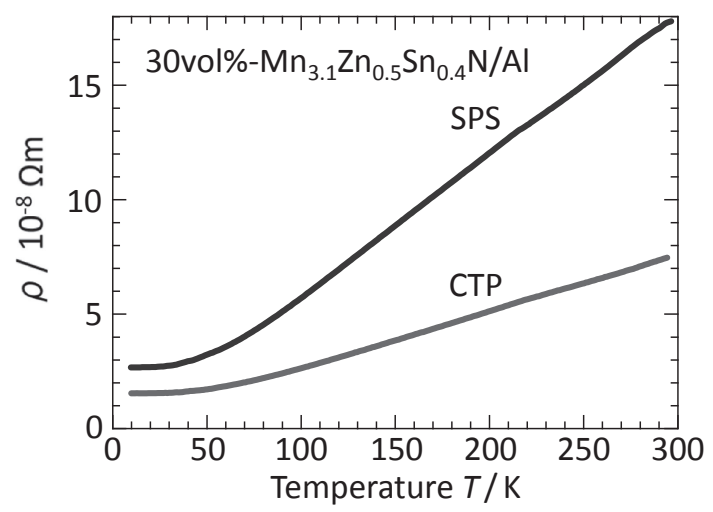

Fig. 5 Electrical resistivity $\rho$ of 30 vol\%- $\mathrm{Mn}_{3.1} \mathrm{Zn}_{0.5} \mathrm{Sn}_{0.4} \mathrm{~N} / \mathrm{Al}$ composites formed by SPS and CTP. composites obtained from this experiment were $17.8 \mu \Omega \mathrm{cm}$ for SPS and $7.5 \mu \Omega \mathrm{cm}$ for CTP at $295 \mathrm{~K}$. Both are higher than $\rho_{\text {ROM. }}$. The electrical resistivity of the current-sintered 30 vol\%- $\mathrm{Mn}_{3} \mathrm{Zn}_{0.5} \mathrm{Sn}_{0.5} \mathrm{~N} / \mathrm{Al}$, ${ }^{24)}$ which does not control the filler particle size similar to the present SPS composite, is reported to be about $12.5 \mu \Omega \mathrm{cm}$. In addition, the resistivity of 25 vol\%- $\mathrm{Mn}_{2.85} \mathrm{Cu}_{0.1} \mathrm{Zn}_{0.55} \mathrm{Sn}_{0.4} \mathrm{~N} / \mathrm{Cu}$ composite was about $7 \mu \Omega \mathrm{cm},{ }^{26)}$ in which the matrix of $\mathrm{Cu}\left(\rho=1.6 \mu \Omega \mathrm{cm}^{36}\right)$ at room temperature) has higher electrical conductivity than Al. The filler particle size was not controlled. In this case, it is estimated that $\rho_{\mathrm{ROM}}=3.5 \mu \Omega \mathrm{cm}$. Although some room for improvement remains, the present CTP probably shows better electrical conductivity than these past composite materials.

The Wiedemann-Franz law predicts the thermal conductivity $\kappa$ of the composites as $\kappa_{\mathrm{WF}}=41 \mathrm{~W} \mathrm{~m}^{-1} \mathrm{~K}^{-1}$ for SPS and $\kappa_{\mathrm{WF}}=96 \mathrm{~W} \mathrm{~m}^{-1} \mathrm{~K}^{-1}$ for CTP. The actually measured thermal conductivity of $30 \mathrm{vol} \%-\mathrm{Mn}_{3} \mathrm{Zn}_{0.7} \mathrm{Ge}_{0.3} \mathrm{~N} / \mathrm{Al}$ was about $47 \mathrm{~W} \mathrm{~m}^{-1} \mathrm{~K}^{-1}{ }^{25)}$ Reflecting its high electrical conductivity, CTP composites can be characterized as superior to previously reported composites in terms of thermal conductivity.

Then we evaluated how chemical reactions progressed between the matrix and the filler when forming composites. Figure 6 shows SEM images of the nitride grains, both about $40 \mu \mathrm{m}$, for the SPS (a) and CTP (b) composites. The composition analysis by EDX was performed on the region
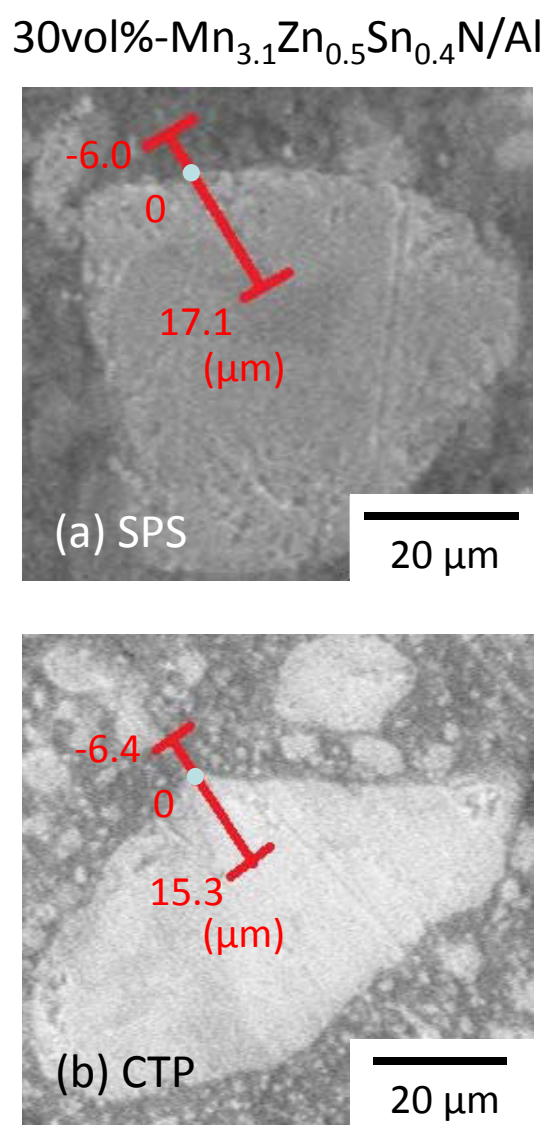

Fig. 6 SEM images of the nitride grains in $30 \mathrm{vol} \%-\mathrm{Mn}_{3.1} \mathrm{Zn}_{0.5} \mathrm{Sn}_{0.4} \mathrm{~N} / \mathrm{Al}$ composite formed by SPS (a) and CTP (b). EDX-analysis points are spaced evenly on lines shown in the figure. Solid circles correspond to $0 \mu \mathrm{m}$ points. The positive and negative positions respectively correspond to the filler and matrix regions. 


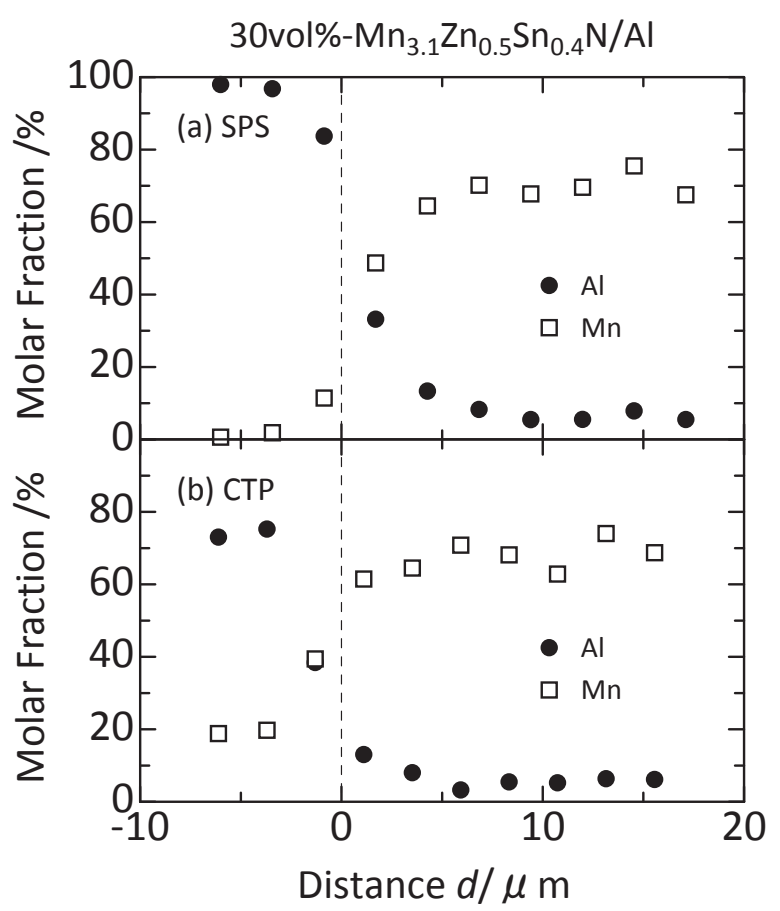

Fig. 7 Molar fraction of Al (solid circle) and Mn (open square) elements inside and outside of the grain: (a) SPS and (b) CTP.

of about $20 \mu \mathrm{m}$ near the interface shown by the red line. Here, the discussion is based on the mole fractions of $\mathrm{Al}$ and $\mathrm{Mn}$, which have high contents (Fig. 7). The position of the origin $0 \mu \mathrm{m}$ (shown as a circle in Fig. 5) corresponds to the interface. The position is indicated as positive on the filler side and negative on the matrix side. Results confirmed that the dominant element is altered from $\mathrm{Al}$ to $\mathrm{Mn}$ as the position passes the origin $0 \mu \mathrm{m}$ from minus to plus. Both transition regions are approximately $7-10 \mu \mathrm{m}$. In the case of $25 \mathrm{vol} \%$ $\mathrm{Mn}_{2.85} \mathrm{Cu}_{0.1} \mathrm{Zn}_{0.55} \mathrm{Sn}_{0.4} \mathrm{~N} / \mathrm{Cu}$, which was evaluated similarly, it was about $10 \mu \mathrm{m} .{ }^{26)}$ It is noteworthy that the widths of the transition region are similar between SPS and CTP, despite the large difference in their processing temperatures. Careful discussion must address the high Mn content on the matrix side of CTP compared to that of SPS. For SPS, the matrix side can be regarded as almost pure $\mathrm{Al}$ when it is about $3 \mu \mathrm{m}$ away from the interface, but in CTP, even when it is distant by $3 \mu \mathrm{m}$, finite $\mathrm{Mn}$ is apparently contaminated. In CTP, small particles of filler crushed during the forming process are present nearby. In addition, the filler might be present immediately below the position that is the matrix on the SEM micrograph. The factors presented above should also be considered for the exudation of $\mathrm{Mn}$ into the matrix.

\section{Discussion}

The conditions for electric-current sintering, which is the comparison target of CTP, were determined in light of past studies. $^{22,23,25)}$ Earlier reports have described that manganese nitrides and $\mathrm{Al}$ can be composited in a $T$ range of approximately $673 \pm 50 \mathrm{~K}$. Within this range, the thermal expansion suppressing ability of the NTE nitrides is almost identical. At higher $T$, the chemical reaction between the matrix and the filler proceeds. However, if the sintering is performed at a lower $T$, then it seems at first glance that the chemical reaction at the interface is suppressed and that thermal expansion might also be suppressed down to ROM. In that case, the mechanical properties are sacrificed, which eliminates its potential role as a structural material. Interface imperfections also have severe adverse effects on conduction properties. For this study, from the viewpoint of practical materials, the SPS composite counterpart was prepared at $733 \mathrm{~K}$, corresponding to the upper limit.

The results presented herein suggest that CTP is superior to SPS in terms of thermal expansion suppressing effect and conductivity. For manganese nitride fillers, which are highly reactive with molten metals, earlier reports have described that crushed filler granules are ineffective in suppressing thermal expansion because of chemical reactions with the matrix. ${ }^{26)}$ The composition analysis presented herein suggests that exudation of Mn to the matrix side might be greater in CTP than in SPS. Furthermore, earlier studies have suggested that mechanical crushing degrades the thermal expansion suppression capability of the manganese nitrides. ${ }^{38)}$ Nevertheless, it is noteworthy that CTP exhibited more effective suppression of thermal expansion over SPS. In the case of CTP, both the formation of a strong and stable interface and the sufficient effect of suppressing thermal expansion are achieved. The intensities of the XRD peaks that newly appeared by forming composites seems to be almost identical between CTP and SPS, which suggests that the amounts of reactant are about the same for both composites. However, because part of filler is crushed during the CTP process, it should be examined that the matrix-filler interface increases accordingly in the CTP composite. Therefore, given the same degree of chemical reactivity, the amounts of reactant should increase. The similar peak intensities rather suggest that the lower process temperature of CTP compared to that of SPS suppresses extra chemical reactions. The superiority of CTP is expected to be demonstrated in future mechanical characterizations. In fact, for metal materials such as $\mathrm{Al}$, torsion processing methods have been found to improve mechanical strength. ${ }^{27,29,34)}$

The wide peak width in the XRD profile of the CTP composite suggests that the crystallinity is damaged. The stress applied during the process might affect the crystal lattice of $\mathrm{Al},{ }^{31)}$ which has lower hardness than the filler, and which lowers the conductivity. ${ }^{39)}$ Furthermore, SEM micrographs reveal that some, albeit few, pores remain. Still the interface is not in such poor condition. The residual pores can also degrade conductivity. In the CTP method, parameters such as the forming temperature, rotation speed, and number of CTP turns strongly influence the characteristics. Optimization of these parameters can be expected to increase conductivity while maintaining the thermal-expansionsuppressive effects.

\section{Conclusion}

Manganese nitride filler showing giant negative thermal expansion (NTE) was composited with aluminum powder using compressive torsion processing (CTP). In the CTP composite, the manganese nitride suppressed the thermal expansion of aluminum more effectively than in the 
conventional electric-current sintered body. Results confirmed that the electrical resistivity and residual pores were reduced in the CTP composite. The results presented herein demonstrate that CTP is effective for forming metal matrix composites containing giant NTE materials such as manganese nitrides, in which chemical reactions with metal matrices at high temperatures have so far made it difficult to form composites with metals.

\section{Acknowledgments}

The authors are grateful to Y. Yokoyama for fruitful discussion. They also would like to thank T. Hamada, N. Sugimoto, K. Kuzuoka, T. Sugiura, and M. Ozeki for their assistance with experiments. This work was supported financially by Grants-in-Aid for Scientific Research (Nos. JP18H01351, JP19H05625, and JP20H00346) from MEXT, Japan.

\section{REFERENCES}

1) K. Takenaka: Front. Chem. 6 (2018) 267.

2) F.H. Gillery and E.A. Bush: J. Am. Ceram. Soc. 42 (1959) 175-177.

3) T.A. Mary, J.S.O. Evans, T. Vogt and A.W. Sleight: Science 272 (1996) 90-92.

4) S. Iikubo, K. Kodama, K. Takenaka, H. Takagi and S. Shamoto: Phys. Rev. B 77 (2008) 020409(R).

5) M. Azuma, K. Oka and K. Nabetani: Sci. Technol. Adv. Mater. 16 (2015) 034904.

6) Y.Y. Zhao, F.X. Hu, L.F. Bao, J. Wang, H. Wu, Q.Z. Huang, R.R. Wu, Y. Liu, F.R. Shen, H. Kuang, M. Zhang, W.L. Zuo, X.Q. Zheng, J.R. Sun and B.G. Shen: J. Am. Chem. Soc. 137 (2015) 1746-1749.

7) J. Chen et al:: Nat. Commun. 8 (2017) 14441.

8) K. Takenaka, Y. Okamoto, T. Shinoda, N. Katayama and Y. Sakai: Nat. Commun. 8 (2017) 14102.

9) H. Yamamoto, T. Imai, Y. Sakai and M. Azuma: Angew. Chem. Int. Ed. 57 (2018) 8170-8173.

10) J. Tani, H. Kimura, K. Hirota and H. Kido: J. Appl. Polym. Sci. 106 (2007) 3343-3347.

11) K. Nabetani, Y. Muramatsu, K. Oka, K. Nakano, H. Hojo, M Mizumaki, A. Agui, Y. Higo, N. Hayashi, M. Takano and M. Azuma: Appl. Phys. Lett. 106 (2015) 061912.

12) J.C. Lin, P. Tong, K. Zhang, X.H. Ma, H.Y. Tong, X.G. Guo, C. Yang, Y. Wu, M. Wang, S. Lin, W.H. Song and Y.P. Sun: Compos. Sci. Technol. 146 (2017) 177-182.

13) K. Takenaka, M. Sato, T. Nishikawa, T. Omura, N. Yamada, Y Yokoyama, N. Katayama and Y. Okamoto: J. Jpn. Inst. Met. Mater. 84
(2020) 161-166.

14) H. Holzer and D.C. Dunand: J. Mater. Res. 14 (1999) 780-789.

15) A. Matsumoto, K. Kobayashi, T. Nishio and K. Ozaki: Mater. Sci. Forum 426-432 (2003) 2279-2284.

16) Z.W. Xue, L.D. Wang, Z. Liu and W.D. Fei: Scr. Mater. 62 (2010) 867870 .

17) X.R. Shan, R.J. Huang, Y.M. Han, C.J. Huang, X.P. Liu, Z.G. Lu and L.F. Li: J. Alloy. Compd. 662 (2016) 505-509.

18) K. Takenaka, M. Ichigo, T. Hamada, A. Ozawa, T. Shibayama, T. Inagaki and K. Asano: Sci. Technol. Adv. Mater. 15 (2014) 015009.

19) K. Takenaka: Sci. Technol. Adv. Mater. 13 (2012) 013001.

20) C. Zhou, Q. Zhang, X. Tan, S.H. Deng, K.W. Shi, C. Wang and G.H. Wu: Materialia 6 (2019) 100289

21) L. Ding, X. Wang, Y.Y. Na, L.H. Chu and J. Yan: Scr. Mater. 65 (2011) 687-690.

22) K. Takenaka, T. Hamada, D. Kasugai and N. Sugimoto: J. Appl. Phys. 112 (2012) 083517

23) N. Sugimoto, T. Hamada and K. Takenaka: J. Jpn. Inst. Met. Mater. 77 (2013) 75-79.

24) J. Yan, Y. Su, C. Wang, L.H. Chu, Z.X. Shi, S.H. Deng, K.W. Shi and H.Q. Lu: Scr. Mater. 84-85 (2014) 19-22.

25) J.J. Miao, J.Q. Liu, X. Wu, H. Zou, D.W. Sha, J. Ren, Y. Dai, X.H. Yan and X.N. Cheng: Sci. Eng. Compos. Mater. 25 (2018) 95-100.

26) K. Takenaka, K. Kuzuoka and N. Sugimoto: J. Appl. Phys. 118 (2015) 084902 .

27) A.P. Zhilyaev and T.G. Langdon: Prog. Mater. Sci. 53 (2008) 893-979.

28) K. Edalati and Z. Horita: Mater. Sci. Eng. A 652 (2016) 325-352.

29) J.M. Cubero-Sesin and Z. Horita: Mater. Sci. Eng. A 558 (2012) 462471.

30) K. Edalati, H. Iwaoka, S. Toh, K. Sasaki and Z. Horita: Mater. Trans. 54 (2013) 1540-1548.

31) K. Oh-ishi, K. Edalati, H.S. Kim, K. Hono and Z. Horita: Acta Mater. 61 (2013) 3482-3489.

32) Y. Kume, M. Motohashi, M. Kobashi and N. Kanetake: Mater. Sci. Forum 654-656 (2010) 1247-1250.

33) S. Tsuda, M. Kobashi and N. Kanetake: Mater. Trans. 47 (2006) 21252130 .

34) N. Kanetake, Y. Kume, S. Ota and R. Morimoto: Procedia CIRP 18 (2014) 57-61.

35) T.A. Hahn: Thermal Expansion of Metal Matrix Composites, in Metal Matrix Composites: Mechanisms and Properties, (Academic Press, Cambridge, 1991) pp. 329-355.

36) N.W. Ashcroft and N.D. Mermin: Solid State Physics, (W. B. Saunders Company, Philadelphia, 1976).

37) K. Takenaka, A. Ozawa, T. Shibayama, N. Kaneko, T. Oe and C. Urano: Appl. Phys. Lett. 98 (2011) 022103.

38) M. Ozeki, V. Warne-Lang, H. Tsukasaki, Y. Sakai, N. Katayama, Y. Okamoto, M. Azuma, S. Mori and K. Takenaka: Appl. Phys. Express 13 (2020) 075501

39) R. Haraguchi, Y. Yoshimatsu, T. Nagaoka, M. Arita, K. Edalati and Z. Horita: J. Mater. Sci. 52 (2017) 6778-6788. 